\title{
Human Resources Management Review on Netflix
}

\author{
Nanda Hidayati \\ ${ }^{I}$ STIE IPWIJA, Jakarta, Indonesia \\ ${ }^{*}$ Corresponding author. E-mail: nanda.assalaam@gmail.com
}

\begin{abstract}
Human capital is one of an organization's most crucial assets. In other words, an organization's success is directly related to its workers' performance. As a result, managers, and specialists attempt to ascertain the most significant aspects of employee motivation. The effects of working circumstances, job content, and career advancement on job motivation and performance are examined in this study. The management system offered by Netflix may be a little contrary to the standards usually set by human resources (HR) practitioners. Being in a competitive climate and technological development, the previous practices that might have been effective now look outdated and not applicable in the current and future business environment. So, the role of HR in the future seems no longer as a Business Partner. It should become an 'Enabling Business.' Netflix has proven that HR can be an enabling business.
\end{abstract}

Keywords: Human Resources, Netflix, Working Conditions, Job Content, Work Motivation.

\section{INTRODUCTION}

Netflix is a media company for movie lovers. Netflix has successfully transformed into one of the Video on Demand (VoD) providers with the most operational areas worldwide. They made a significant transformation to get the best team in their organization. There is no hesitation. The company will only hire players (grade) "A" to get the best practices. Regardless of how much an employee contributed to the prior organization, the employer will discharge them if their abilities are no longer required. Letting go of people whose talents are no longer necessary for the firm's evolution (as Netflix's technology advancements demonstrate) is a win-win situation for both the company and the employees. In addition to companies experiencing losses.

It is not just the company that suffers, and employees will also experience a phase of frustration when forced to try to achieve performance beyond their reach. For example, companies face challenges transitioning from DVD delivery content via cyberspace to VoD. Companies need to find people who are very experienced with cloud services that will enable them to operate on a massive scale. Netflix's best practice is to strive to put together a great team of employees dedicated to the company's benefit.
Netflix enables customers to watch their favorite episodes from virtually any location, at any time, and on practically any device (smartphones, smart TVs, tablets, PCs, and laptops). One of Netflix's added values is that it is content free of advertisements, so viewers do not have to wait for television series broadcasting schedules and can decide for themselves the content they want to enjoy. Along with improving the user experience, Netflix continuously attempts to strengthen its reputation as a quality corporation wanted by individuals, particularly those in their twenties and thirties. As a result, they are now well known for their culture.

\section{LITERATURE REVIEW}

\subsection{Human Resource Management}

The value of human resources in a company is increasingly recognized, to the point that individuals are viewed as the organization's most vital resource. [1]. Humans are the foundation for an organization because that makes the organization more developed. Human resource management includes the management of workforce, personnel, employees, employees, or members so that it can more easily identify the source from which the person was obtained, determine or calculate how many employees are needed, plan and analyze the fulfillment of needs to evaluate the work results [2]. 
Human resource management (HRM) implements procurement, training, and development activities and compensation and other human resources (HR)-related operations to develop productive individuals [3]. Human resource management encompasses all management choices and activities that directly impact human capital. HRM is required to maximize the effectiveness of an organization's human resources. The objective is to establish a functional work unit inside the company [4].

Human resource management is a process related to implementing management functions ranging from planning, organizing, directing to supervising, which plays a vital role effectively and efficiently in supporting the achievement of individual and organizational goals. For an organization, human resource management concerns the overall human affairs in the organization to take an active role in achieving the goals that have been set. Therefore, if the human resources in the organization are managed and utilized correctly, the organization will be able to run its business optimally.

\subsection{Netflix Company}

Netflix, according to Nugroho, is a subscription-based movie streaming service that offers the newest films and television episodes daily. Netflix is a service based in the United States, namely in California. It began as a DVD rental store before expanding into the internet market. Netflix has just recently been available to internet users in various Asian nations. Indonesia is no different. Netflix arrived and officially launched its service in Indonesia on Friday, February 5, 2016. Netflix subscriptions start at Rp. 109,000 for the basic package and go up to Rp. 169,000 for the premium plan [5].

In 1999, Netflix started its business activities by providing DVD rental services. Unlike the DVD rental business, Netflix does not have a physical store. DVD orders are made via email, followed by sending physical DVDs to customers. By paying a predetermined subscription fee every month, customers are given the freedom to rent any number of movie titles. In 2007, Netflix began providing a streaming service to reduce the cost of shipping DVDs. It started with 2,000 titles which then showed a good response from customers so that it rose rapidly to reach 20,000 titles within three years. The trend of the "home entertainment" market continues to be in demand, so that Netflix is starting to become the leading choice for digital entertainment connoisseurs.
In the current digital era, Internet users in Indonesia use it more to watch movies/videos, and one of the companies that provides video streaming services is Netflix [6]. Netflix is one of the most popular video-on-demand subscription services, with over 151 million paid customers in over 190 countries and a diverse selection of television shows, documentaries, and feature films in various genres and languages [7]. Since first entering Indonesia in 2016, Netflix has attracted a lot of media attention because of the blocking from the Telkom Group, which incidentally is the largest telecommunications and network service provider in Indonesia [8].

Netflix itself is a form of a business entity located and proliferating abroad, expanding its services in every country, including Indonesia. Throughout 2019, the number of Netflix users increased to 8.8 million. Which previously numbered 7.6 million subscribers. Meanwhile, the number of paid users of the Netflix application worldwide is 167 million. The total number is 100 million, not from the United States. Revenue from Netflix alone in 2019 reached 5.47 billion US dollars, and EPS was only estimated at 1.30 US dollars. From this achievement, we can see the soaring revenue from Netflix itself, which even exceeded previous expectations where the analysis predicts that Netflix's revenue will reach US\$5.45 billion [9].

\subsection{HR Management at Netflix}

\subsubsection{Talent Management Strategy: No Compromise}

Most organizations sometimes overlook talent management as a strategic endeavor. This issue is particularly prevalent in media firms, an industry with a low rate of new hires. Netflix is different from other companies, and they are emphatically against the idea. In 2001 they laid off a third of the company's employees. When a company is on the verge of bankruptcy, all the remaining employees come together to build the awareness that those remaining are high-performing employees. It tells us that the best thing we can do for the business is recruiting just the finest performers. Please take advantage of the complex economic environment to their advantage.

Thus, what makes workers exceptional? The majority of firms are unaware that exceptional workers are subjective. Its regular recruiting procedure evaluates a candidate's qualities only based on their $\mathrm{CV}$ and educational credentials and, if relevant, recommendations. Few employers actively strive to match employees' talents (which are not necessarily represented in academic credentials) 
with job requirements. The descriptions are written information outlining duties and responsibilities, working conditions, job relationships, and job aspects in a particular position in the organization [10]. A terrific employee who advances to the level of player A in one firm is likely to advance to the level of player B in another, and vice versa. The effect of hiring the right talent is multiplicative. If the team is filled with the right people and is kept motivated about developing their talents and challenges, everyone will be great at facing tough challenges. Thus, once you have identified the most incredible talent, you must empower them to address the organization's challenges.

\subsubsection{Forming High Performance}

At Netflix, a great workplace is not defined as a workplace with great benefits, a beautiful office, or a delicious cafeteria. However, the great workplace at Netflix is what if every employee could efficiently attract and retain amazing coworkers. There is a phrase that is always emphasized by the CEO that the Netflix leader must be able to achieve, maintain or 'reduce' intelligently so that Netflix will have a star employee in every position. The test given by the leaders/managers at Netflix was: "Which of my employees, if they were going to leave this company for a similar type of job at another company, would I keep them at Netflix?"

\subsubsection{Giving freedom and responsibility (Freedom \& Responsibility)}

If the company gets bigger, then the complexity tends to increase. Netflix initially provided an annual leave/off/vacation policy for employees. However, this policy was later abolished. Why? Because employees at Netflix used to work online every night, sometimes on holidays, serving email, occasionally taking breaks. So, Netflix does not track the number of hours its employees work but gives employees the freedom to take their number of days off. For example, employees can take an extended vacation and return to work with fresh ideas or inspiration for the company. The bottom line is that Netflix does not have a dress code for employees to wear, but that does not mean you can be naked in the office.

So, what are the rules for official travel, relationships with vendors/suppliers, or others that the company generally gives strict rules/standards? This is the exciting part Netflix's general regulations on spending, entertainment, gifts, and travel are available here. When employees travel on business, they must feel like spending their own money. The expenses incurred are required and essential for the business's operations. For instance, if you are at a premium restaurant, it is reasonable for the sales marketing staff to interact with customers. However, it is inappropriate for Netflix workers to interact alone or with colleagues. Act in the Best Interest of Netflix -Apply in the best interest of Netflix.

Working conditions influence work motivation with a positive regression direction. This can be interpreted if working conditions are getting better, then work motivation will increase. This finding supports the opinion of [11], [12], [13], [14] states that an essential factor that drives work motivation is working conditions. If the working conditions provided are good enough, it will influence work motivation.

\subsubsection{Compensation philosophy on Top Market}

At Netflix, there are no performance bonuses or annual bonuses. They believe that it is not necessary if you hire the right employees. The philosophy at Netflix is, if you hire employees who are mature and put the company's interests first, then an annual bonus will not make the employee work harder or be more intelligent. At Netflix, they let employees take interviews with competing and similar companies to determine the market pay for the job. Even Netflix's HR department asked them to share what competitors are offering because that is a valuable source of information. HR practitioners of other companies usually avoid this, but on Netflix, it is allowed. At Netflix, they trust the wage market more.

\section{RESEARCH METHODS}

The following section details the methods used to ensure that this study is conducted systematically, directed, and transparently. The following diagram depicts the course of this study:

1) Search for news articles and journal articles. Journal searches were conducted using a variety of sources. The following keywords were used to locate relevant journals: profiles, human resource management at Netflix and other firms, and related publications.

2) Selecting articles. Following that, relevant news items and journals are picked from the results of the search phase.

3) Conduct a review of the selected article. The articles that were discovered and selected are then analyzed to create a corporate profile and highlight the human resource management practices employed since the industry began.

4) Gaps analysis. The next step is to analyze the review results to search for gaps to expand Netflix's business. 
5) Improvements. The final stage is to make recommendations based on gaps at HRM in Netflix to achieve its business goals and direction in its business processes.

\section{RESULTS AND DISCUSSION}

\subsection{Exciting things in HR Management Netflix}

Netflix has good management because it can penetrate almost all mass media, especially in subscription tv and video streaming. The number of consumers who subscribe to Netflix streaming access in Indonesia, Netflix content that has a high rating, Netflix has the availability of qualified technology so that it can penetrate almost all mass media, especially in visual form, can reduce unemployment in Indonesia due to the expansion carried out by Netflix [5]. Netflix has very interesting profiled, my list, and continue features that can make it easier for users to set customized profiles such as profiles for children and adults and manage a list of movies or movies series they want to watch. Netflix's ideas and efforts have elevated the company to the top spot in the Indonesian SVOD (Subscription video-on-demand) industry. This is due to Netflix's hegemony, particularly original programming. By refining its strategy, Netflix may continue to internationalize its product and service offerings in Indonesia [15].

Netflix's strength lies in its original content continuously produced and has good quality. Netflix is a diverse application because it presents a range from the West and films from Asia (including Indonesia) [9].

According to merdeka.com's Netflix page, Netflix was founded on April 14, 1998, with 30 personnel. At the time, around 925 films were available for internet rental at the cost of approximately Rp. 40,000 per rental and approximately Rp. 20,000 for delivery. In September 1999 , the notion of a monthly subscription was established. Netflix then sold 5.5 million shares in its initial public offering (IPO) on May 29, 2002. The general public has embraced Netflix. This is seen by the cumulative [16].

\subsection{Netflix subscribers recorded in 2005, reaching 4.2 million.}

Since 2008, Netflix has also partnered with electronics manufacturers to provide its users with streaming programs. Netflix collaborates with the Xbox 360, Blu-ray disc players, set-top boxes for televisions, and the Apple Macintosh computer. A year later, the PS3 and various additional internet connections were added. It does not end there. Netflix became accessible on the Apple iPad, iPhone, and iPod Touch, as well as the Nintendo Wii, in 2010. Netflix has opened offices in Canada, Latin America and the Caribbean, the United Kingdom, and Ireland since the same year. Additionally, there is the Nintendo Wii. Netflix has opened offices in Canada, Latin America and the Caribbean, the United Kingdom, and Ireland since the same year. Netflix had topped 30 million users globally in 2012 [16].

\subsection{Similarities and Differences with Other Film Industries}

Netflix and Viu are the most popular paid video-on-demand service platforms, with iFlix, Google Play Movies \& TV, iTunes, Viki, Tribe, and Catchplay following behind [17]. There are several differences between Catchplay and other similar features in IndiHome, such as Iflix and Netflix. However, the critical difference is in the service. Iflix and Netflix are more focused on TV series, while Catchplay focuses on streaming Blockbuster movies [18]. It can be seen in this study that Video on Demand both broadcasts tv series in priority. The difference with Catchplay is that it focuses more on streaming Blockbuster movies. According to Khafid, the similarities with other film industries are streaming services and similar things, namely a). Subtitles in English and the language of each country of service. b). Ad-free. c). I can watch offline. d). Can use $4 \mathrm{~K}$ resolution (there is an extra charge for Netflix). e). Child mode (to control the child to watch according to his age). The styles are the same in terms of the type and amount of content, except that Netflix has 47 thousand series and four thousand films, and Disney+ has 7,500 serial episodes and 500 movies. Netflix is available in several countries and territories, totaling 190. Netflix is unavailable in only four countries: China, North Korea, Crimea, and Syria. The United States, Canada, the Netherlands, Australia, New Zealand, the United Kingdom, Ireland, Germany, Italy, Spain, Austria, Switzerland, India, France, Japan, Belgium, Portugal, Luxembourg, and the Nordic nations are among the countries that may access Disney+ [19].

\subsection{Similarities and Differences with Other Industries}

Netflix and Digital TV have something in common. Namely, both services are in the form of shows to be watched. According to [20], Streaming services require internet access so that they require internet data to enter the network, and in subscribing, they have a predetermined bill while TV broadcasts. This digital is free of charge and does not require 
Internet access or requires a smart TV with an internet connection and using satellite or satellite dishes. According to CNN Indonesia (2021), Digital TV and Video Streaming Both use the latest technology. Many people find it difficult to distinguish between digital TV and video streaming services. Some even consider the two the same. One of the differences between digital TV and video streaming services lies in the subscription system. Streaming services generally charge a fee to subscribe, but not with digital TV [21].

The second difference lies in the use of the internet needed to access streaming services. Digital $\mathrm{TV}$ does not require internet access or must use an intelligent television connected to the internet. Digital TV broadcasts are terrestrial broadcasts commonly seen every day using digital frequencies. Older model televisions can still be used to capture digital TV broadcasts if they are connected to a settop box. The set-top package combines the television set with the UHF antenna. The set-top box is changing the transmission from analog to digital broadcasts. Digital TV does not require internet access or must use an intelligent television connected to the internet. Digital TV broadcasts are terrestrial broadcasts commonly seen every day using digital frequencies. If linked to a set-top box, older model televisions can still be used to record digital television broadcasts. The set-top box is the component that links the television set to the UHF antenna. The set-top box is changing the transmission from analog to digital broadcasts. Digital TV does not require internet access or must use an intelligent television connected to the internet. Digital TV broadcasts are terrestrial broadcasts commonly seen every day using digital frequencies. Older model televisions can still be used to capture digital TV broadcasts if they are connected to a set-top box. The set-top package combines the television set with the UHF antenna. The set-top box is changing the transmission from analog to digital broadcasts.

\subsection{Improvements for Netflix}

Previous research has several suggestions regarding Netflix services, including 1). Seeing the many competitors who offer similar services, such as Netflix, Netflix should improve prices to provide more competitive prices than its competitors. 2). Regarding the offline mode feature that was just launched in December 2016, it would be better if this feature was improved in extending video storage time and not limiting content that can be watched offline so that Netflix users will be more flexible in accessing downloaded content. 3). It is advisable to expand in Netflix subscription registration so that registration is not done using only a credit card [22].

Netflix has offered several packages where users can choose according to their purchasing power so that, in terms of Perceived Price, the company can make improvements in terms of price so that the price offered is more affordable than its competitors because many competitors have similar services to Netflix, for example, the company can offer family packages. The package can be accessed by several users at once so that the subscription price paid by each customer becomes cheaper. Netflix can carry out promotional activities in advertisements in several media such as newspapers, magazines, and billboards to make Netflix better known by the Indonesian people [23].

Netflix must comply with the laws and regulations owned by the Indonesian government to expand into the Indonesian market. There need to be clear regulations between Netflix and the Indonesian government and private parties to avoid disputes in its implementation. Netflix itself must sort out content and shows that will be marketed to Indonesia to have no complaints about its performance. Establish cooperation with companies and related parties in Indonesia, helping to develop the economy in Indonesia [5].

\subsection{What to learn from Netflix for Other Industries}

Netflix is a streaming service that offers Netflix original films and shows, material produced by Netflix, and collaborations with worldwide filmmakers (Global Film Maker) to differentiate itself from other streaming services. Netflix's original films introduce audiences to a worldwide culture. In Indonesia, Netflix premiered a Netflix original film named "The Night Comes for Us" for the first time [24]. Other studies concur: Netflix's edge over other streaming services is that it produces Netflix original films and series and partners with worldwide producers. Netflix's original films introduce audiences to a worldwide culture. Netflix officially and for the first time in Indonesia launched a Netflix original film titled "The Night Comes for Us" [25]. One strategy to increase value and competitive advantage is to apply brand equity [26]. Nathaniel's research said respondents agree that after seeing Netflix ads on Youtube Ads, respondents pay attention to the business of marketers, the advantages of the services offered by Netflix, the characteristics of the Netflix service, and have started to pay attention to the price of the service [27]. 


\section{CONCLUSION}

The management system offered by Netflix may be a bit contrary to the standards that HR practitioners usually set. This is where the difference is. Being in a competitive climate and technological development, the previous practices that might have been effective now look outdated and not applicable in the current and future business environment. So, the role of HR in the future seems no longer as a Business Partner. It should become an 'Enabling Business. Netflix has proven that HR can be an enabling business.

\section{REFERENCES}

[1] Azalia DW. (2020). Analysis of Factors Affecting Purchase Decisions on Video on Demand Services (Study on Netflix Users). Diponegoro Journal of Management. Volume 9, Number 2

[2] Dessyana E. (2020). Word of Mouth's Relationship to Interest in Buying Netflix Subscriptions. Essay. Communication Studies Program, Faculty of Social and Political Sciences, Sriwijaya University

[3] Fawzia U. (2020). The Identification Of "The Art of War" Military Strategy on Netflix's Business Strategy. Strategic Global. Vol 14, No

1.

=http://dx.doi.org/10.20473/jgs.14.1.2020.14 3-160

[4] Hasan, V. (2017). Analysis of Factors Affecting Willingness to Subscribe: A Study on Netflix's Video on Demand Service. Ultima Management: Journal of Management Science, $9(1)$

$22-$ 38.https://doi.org/https://doi.org/10.31937/m anajemen.v9i1.595.

[5] Ramadhan, MR, \& Kristian S, DO (2020). Analysis of Netflix Taxation in Indonesia. National Symposium on State Finance, 2(1), 59-77.

Retrieved fromhttps://jurnal.bppk.kemenkeu.go.id/snkn /article/view/522

[6] Michael T. (2017). Human Resources Management (Revised Edition). CV. RA De. Rozarie. Surabaya

[7] Nathaniel E, Kusuma S. (2020) The Influence of Mobile Advertising on Interest in Buying Netflix Services During the Covid-19 Pandemic. Communication Perspective: Journal of Political Communication and Business Communication, Vol 4 No 2
[8] Nugroho YM, Jumhur HM. (2017). Analysis of the Eligibility of Opening Netflix Access in Indonesia Viewed from Telecommunication Regulations. eProceedings of management. Vol 4, No 3

[9] Putri Nuriska, F., \& Azizah, N. (2021). Analysis of Continuance Intention to Use Video on Demand Service with Theory of Planned Behavior Approach (Case Study on Netflix Application Users in Surabaya City). Journal of Syntax Admiration, 2(2), 229-248. Retrieved

fromhttps://jurnalsyntaxadmiration.com/inde x.php/jurnal/article/view/180

[10] Prabowo R. (2019) Analysis of the loyalty of the Netflix subscription video-on-demand service users using the extended Unified Theory of Acceptance And Use Of Technology 2 (UTAUT2). Essay. Faculty of Science and Technology Syarif Hidayatullah State Islamic University Jakarta. URIs:http://repository.uinjkt.ac.id/dspace/ha ndle/123456789/47931

[11] Prasetyo FMR., Trianasari N. (2021) analysis of the influence of the involvement of brand equity dimensions on brand equity on video on demand Netflix in Indonesia. eProceedings of management. Vol.8, No.4

[12] Purnomo. 2018. Analysis of the Quality Throughput of Catchplay Useetv Services Using Optical Fiber in the Purwokerto Area. PROCEDURE National Seminar on Sustainable Development of Rural Resources and Local Wisdom VIII. Vol 8, No 1

[13] Utami DB. (2019). Getting to Know Indonesia Through Netflix Original Movies. Journal of Communication ISSN 2085-1979, EISSN 25282727 Vol. 11, No. 1. DOI:http://dx.doi.org/10.24912/jk.v11i1.405 1

[14] Sudarsono BG. (2021). Netflix Data Mining Data Analysis Using Rapid Miner Application. JBASE - Journal of Business and Audit Information Systems, Vol 4, No 1. DOI:http://dx.doi.org/10.30813/jbase.v4i1.27 29

[15] Suryani NK. (2019). Human Resource Management, Applicative Practical Review. Nilacakra Publishing house. Badung.

[16] SUSAN, E. (2019). Human Resource Management. Adaara: Journal of Islamic Education Management, 9(2), 952-962. two:https://doi.org/10.35673/ajmpi.v9i2.429 
[17] Silaen R. (2021) Human Resource Management. Widina Bhakti Persada. Bandung.

[18] Syamsurizal. (2016). The Role of Human Resource Management in Organizations. Journal of Warta Dharmawangsa No. 49. DOI:https://doi.org/10.46576/wdw.v0i49.15 5

[19] Yusuf NA., Indrawati. (2019) Analysis of the Factors Influencing the Formation of Subscription Interest in the Video-OnDemand Industry in Indonesia. Almana: Journal of Management and Business, Vol. 3 No. 1

[20] Www.glassdoor.com

[21] J Hasibuan, SP Malay. 2005. Human Resource Management. Jakarta: PT. Earth Literature.

[22] Reed Hastings, Erin Meyer. 2020. No Rules Netflix Rules and the Culture of Reinvention. New York: Penguin Press.

[23] Gobel, Hussein. (2006), Effect of Compensation Factors, Working Conditions, Employee Development and Rewards on
Hotel Employee Motivation in Biak City, Papua, Journal of Management Applications, Vol. 3, No. 3, pp. $228-234$.

[24] Majid, NA, Clear, ZA, Azman, N., and Rahman, S. (2010), "Communication Skills and Work Motivation Amongst Expert Teachers, Procedia Social and Behavioral Sciences, Vol. 7, pp. 565-567

[25] Djumadi (2006), Effect of Working Conditions and Job Satisfaction on Employee Performance of Non-formal Education Institutions in East Java, Journal of Management Applications, Vol. 4, No. 3, pp. $441-420$.

[26] Khan, Nadeem Shiraz (2011), The Impact of Work Content, Working Conditions, Career Growth on Employee Motivation, Interdisciplinary Journal Of Contemporary Research In Business, July, vol. 3, No. 3. PP. $1428-1434$.

[27] Ratnasari A, Satvikarani, Sanjaya RB. (2020). Upaya pemungutan pajak terhadap Netflix yang masih belum berbadan usaha tetap. DIVERSI: Jurnal Hukum. Volume 6 Nomor 2. 